\title{
IDENTIFICAÇÃO PRESUNTIVA DE LEVEDURAS DE INTERESSE BIOTECNOLÓGICO EM GRÃOS DE KEFIR
}

\author{
Fernanda Mincev ANTONIASSI, Bruna Letícia MARTINS \& Geisiany Maria de QUEIROZ-FERNANDES \\ Universidade do Sagrado Coração. Bauru, São Paulo, Brasil. \\ *Autor para correspondência: geisiany.queiroz@usc.br \\ DOI: http://dx.doi.org/10.18571/acbm.145a
}

\section{RESUMO}

Os grãos de Kefir são constituídos por uma matriz de polissacarídeos, ricos em micro-organismos simbióticos, gerando após a fermentação de açúcares, uma bebida probiótica que recebe o mesmo nome. A vasta população microbiana presente nestes grãos, incluindo leveduras e bactérias, oferece diversas características únicas à bebida. Estudos apontam que esta possui efeitos antitumorais, anti-inflamatórios, antimicrobiano, modulatório do sistema imune, anticolesterolêmico, dentre outros, devido as moléculas secretadas pelas células microbianas presente no microambiente dos grãos de Kefir. Diante disso, o objetivo deste estudo foi isolar e identificar, presuntivamente, leveduras presentes nos grãos de Kefir, possíveis produtoras de produtos de interesse biotecnológico. Para tanto, foram utilizados grãos da região de Bauru/SP, mantidos em fermentação em água/açúcar mascavo e em leite. Em seguida, os grãos foram triturados e semeados em ágar Sabouraud com cloranfenicol. Os isolados com características macroscópicas leveduriformes foram analisados por exame direto, prova do tubo germinativo e prova da ureia. Os dados obtidos foram comparados com atlas micológicos e chaves de identificação. No total foram isoladas seis colônias diferentes com presença de leveduras como Candida sp. e Saccharomyces sp., que possuem grande relevância para os processos biotecnológicos.

Palavras- chave: Bebida probiótica; Leveduras; Simbiose; Biotecnologia.

\begin{abstract}
Presumptive identification of yeasts of biotechnological interest in kefir grains. Kefir's grains consist of a matrix of polysaccharides, rich in symbiotic microorganisms, generating a probiotic drink that receives the same name, after the fermentation of sugars. The vast microbial population present in these grains, including yeasts and bacteria, offers several characteristics unique to the drink. Studies indicate that it has effects antitumor, anti-inflammatory, antimicrobial, modulatory immune system, anticholesterolemic, among others, due to molecules secreted by the microbial cells present in the microenvironment of Kefir's grains. Therefore, the objective of this study was to isolate and identify, presumptively, yeasts present in the Kefir grains, possibly capable of producing products of biotechnological interest. For this purpose, grains from the Bauru/SP region were used, kept in fermentation in water/brown sugar and milk. Then the grains were seeded and ground on Sabouraud agar with chloramphenicol. Isolates with macroscopic yeast characteristics were analyzed by direct examination, germ tube test and urea test. The data obtained were compared with mycological atlases and identification keys. In total, were isolated six different colonies with the presence of yeasts such as Candida sp. and Saccharomyces sp., which have great relevance for biotechnological processes.
\end{abstract}

Keywords: Probiotic drink; Yeasts; Symbiosis; Biotechnology. 


\section{Introdução}

Os grãos de Kefir, que geram a bebida que leva o mesmo nome, são pequenos grânulos de forma irregular rico em micro-organismos que vivem em simbiose em uma matriz de polissacarídeos, chamada de kefiran, atuando como fermentadores dos açúcares presentes no meio e/ou substrato utilizado para a produção da bebida. Devido a essa simbiose e aos componentes bioativos resultantes do metabolismo microbiológico durante a fermentação, a bebida torna-se probiótica trazendo benefícios à saúde do consumidor (GUZEL-SEYDIM et al., 2011; WESCHENFELDER et al., 2011; LEITE et al., 2013; NIELSEN et al., 2014; PRADO et al., 2015).

Usualmente, a bebida Kefir pode ser preparada em matrizes de fermentação lácteas como, por exemplo, leite de vaca, ovelha e cabra ou não lácteas como soluções de açúcar mascavo, principal substrato alternativo (FIORDA et al.,2017). As características sensoriais relativas à bebida Kefir, descrita como carbonatada, de sabor ácido e de consistência cremosa, é resultado da utilização dos substratos nas rotas bioquímicas dos micro-organismos presentes nos grãos de Kefir que podem ser bactérias e/ou leveduras (DERTLI e ÇON, 2017; FIORDA et al., 2017).

Diferentes espécies de micro-organismos têm sido relatadas como constituintes dos grãos de Kefir obtidos de diferentes regiões. Dentre essas espécies, destacam-se as bactérias ácido láticas como Lactobacillus paracasei, L. parabuchneri, L. casei; bactérias acéticas como Acetobacter lovaniensis e leveduras como Kluyveromyces lactis, Saccharomyces cerevisiae, Lachancea meyersii. Ressalta-se a importância da identificação da comunidades microbianas nos grãos de Kefir, uma vez que a partir disto é possível investigar o potencial biotecnológico desses microorganismos (MAGALHÃES et al., 2011; AHMED et al., 2015; DERTLI e ÇON, 2017 ).

As fontes de carbono disponíveis para o processo de fermentação dos grãos de Kefir influenciam diretamente a frequência das espécies e a concentração dos bioprodutos disponíveis na bebida Kefir (FIORDA et al., 2017). Atribuiu-se as propriedades funcionais e os efeitos benéficos da bebida a sua diversificada composição microbiana, metabólitos secundários, peptídeos bioativos e a matriz kefiran (LEITE et al., 2015). A população microbiana presente nos grãos, incluindo leveduras do gênero Kluyveromyces, Candida, Saccharomyces e bactérias do gênero Lactobacillus, oferece à bebida efeitos antitumorais, anti-inflamatórios, antimicrobiano, modulação do sistema imune intestinal, reduz os níveis de colesterol e melhora a digestão da lactose. Como antimicrobiano, a bebida Kefir tem mostrado atividade contra organismos patogênicos devido a presença de ácidos orgânicos, peróxido de hidrogênio, acetaldeído, gás carbônico, dentre outros. Além disso, alguns micro-organismos isolados dos grãos têm a capacidade de se ligarem a células mutagênicas diminuindo o crescimento de um possível tumor. O consumo regular da bebida mostrou ser capaz de estimular células do sistema imunológico inato do intestino promovendo respostas mediadas por células contra tumores e infecções, auxiliando na homeostase intestinal e, além disso, apresentou atuação positiva sobre a pressão arterial devido a capacidade de dois peptídeos, presentes na bebida Kefir, em inibir a ECA - Enzima Conversora de Angiotensina (GUZEL-SEYDIM et al., 2011; FRANCO, et al., 2013; CARASI et al., 2014; NIELSEN et al., 2014; AHMED et al., 2015; PRADO et al., 2015).

Assim, o objetivo deste estudo foi isolar e identificar, presuntivamente, leveduras presentes nos grãos de Kefir da região de Bauru/SP com capacidade para a produção de moléculas de interesse biotecnológico.

\section{Materiais e Métodos}

\subsection{Obtenção e manutenção dos grãos}

Os grãos foram obtidos na região de Bauru interior do estado de São Paulo e foram cultivados em leite integral UHT e água com açúcar mascavo, em potes de vidro a temperatura 
ambiente. Esses meios de cultivo foram renovados a cada 24 horas, durante 30 dias, lavando-se os grãos em água corrente a cada renovação.

\subsection{Isolamento das leveduras}

Pesou-se $40 \mathrm{~g}$ dos grãos cultivados no açúcar e no leite, separadamente e, em seguida, promoveu-se a maceração dos mesmos com auxílio de almofariz e pistilo, previamente esterilizados. O macerado obtido foi ressuspenso em solução de triptona a $0,1 \%$ e mantidos durante 1 hora a $28^{\circ} \mathrm{C}$, conforme descrito por Diosma (2014). Após este período, os grãos foram semeados em ágar Sabouraud com cloranfenicol e incubados a $35 \pm 2^{\circ} \mathrm{C}$. Após este período, as colônias com características macroscópicas diferentes foram isoladas e mantidas em tubos de ensaio contendo ágar Sabouraud com cloranfenicol.

\subsection{Identificação presuntiva das leveduras}

Para a realização do exame direto, uma pequena porção de cada colônia foi coletada e ressuspensa em salina e observada entre lâmina e lamínula analisando-se as estruturas em microscópio óptico nos aumentos de 10x e 40x, conforme ANVISA (2004).

Para a prova do tubo germinativo cada colônia foi semeada em $500 \mu \mathrm{L}$ de soro humano e incubadas a $37^{\circ} \mathrm{C}$ por 3 horas. Esta prova baseia-se na formação de um filamento fino a partir de um blastoconídio de levedura, onde não se observa nenhuma zona de constrição, indicando a presença de Candida albicans (ANVISA, 2004).

A prova da uréia é uma prova bioquímica utilizada para a identificação de leveduras. De acordo com a ANVISA (2004), a coloração rosa no meio indica reação positiva para a enzima urease, que degrada a uréia em amônia alterando o $\mathrm{pH}$ do meio para alcalino e invertendo o indicador de $\mathrm{pH}$ observado através da mudança de cor.

\section{Resultados}

Observou-se que houve o crescimento de seis colônias com características macroscópicas diferentes após 24 horas e que no exame direto observaram-se diferentes estruturas microscópicas como pseudohifas, blastoconídios e blastoconídios em brotamento, que quando comparados a atlas micológicos, permitiu identificar, presuntivamente, as espécies Saccharomyces cerevisiae, Candida glabrata e Candida krusei, devido a semelhança das estruturas encontradas com as relatadas nestes atlas. Entretanto, notou-se que todas as colônias apresentaram resultado negativo para a prova da ureia, bem como para o teste do tubo germinativo, excluindo a possibilidade de alguma destas leveduras serem Candida albicans (Quadro 1). Assim, como não foi possível encontrar resultados compatíveis para todas as chaves de identificação de leveduras, consideraramse neste estudo, apenas as comparações entre atlas micológicos e o exame direto para a identificação presuntiva das leveduras isoladas dos grãos de Kefir. 


\begin{tabular}{|c|c|c|c|c|}
\hline $\begin{array}{c}\text { Identificação } \\
\text { Presuntiva }\end{array}$ & $\begin{array}{c}\text { Características } \\
\text { Macroscópicas }\end{array}$ & $\begin{array}{c}\text { Características } \\
\text { Microscópicas }\end{array}$ & TG* & Ureia \\
\hline Candida glabrata & $\begin{array}{c}\text { Pequenas, cremosas, lisas, com } \\
\text { bordos lisos e bege }\end{array}$ & $\begin{array}{c}\text { Blastoconídeos e blastoconídeos } \\
\text { em brotamento }\end{array}$ & - & - \\
\hline $\begin{array}{c}\text { Sacharomyces } \\
\text { cerevisiae }\end{array}$ & $\begin{array}{c}\text { Grandes e secas, rugosas, com } \\
\text { bordos crenados, brancas opacas } \\
\text { com centro branco }\end{array}$ & $\begin{array}{c}\text { Blastoconídeos em brotamento, } \\
\text { pseudohifas e blastoconídeos }\end{array}$ & - & - \\
\hline $\begin{array}{c}\text { Sacharomyces } \\
\text { cerevisiae }\end{array}$ & $\begin{array}{c}\text { Grandes e secas, rugosas, com } \\
\text { bordos crenados na cor branca, } \\
\text { incolores com centro } \\
\text { esbranquiçado }\end{array}$ & Pseudohifas e blastoconídeos & - & - \\
\hline $\begin{array}{c}\text { Sacharomyces } \\
\text { cerevisiae }\end{array}$ & $\begin{array}{c}\text { Grandes e secas, rugosas, com } \\
\text { bordos crenados, brancas opacas }\end{array}$ & Pseudohifas e blastoconídeos & - & - \\
\hline $\begin{array}{c}\text { Sacharomyces } \\
\text { cerevisiae }\end{array}$ & $\begin{array}{c}\text { Pequenas, cremosas, lisas, com } \\
\text { bordos lisos e brancas }\end{array}$ & Blastoconídeos & - & - \\
\hline Candida krusei & $\begin{array}{c}\text { Grandes, cremosas, lisas, com } \\
\text { bordos lisos e brancas }\end{array}$ & Blastoconídeos com vacúolos & - & - \\
\hline
\end{tabular}

Quadro 1: Identificação presuntiva de leveduras isoladas dos grãos de Kefir da região de Bauru/SP. *TG = Tubo Germinativo; $* *(-)=$ Negativo.

\section{Discussão}

Em literatura são descritas duas diferentes abordagens para o estudo da microflora dos grãos de Kefir, as técnicas dependentes de cultura, que consistem em métodos de cultivos, e as técnicas independentes de cultura, que consistem, por exemplo, em eletroforese em gel de gradiente desnaturante (LEITE et al., 2012; DERTLI e ÇON, 2017). Neste estudo a avaliação da microflora deu-se por intermédio de técnica dependente de cultura. Foram isoladas seis colônias com características macroscópicas e microscópicas diferentes dos grãos de Kefir obtidos na região de Bauru/SP, identificando, presuntivamente, as espécies Saccharomyces cerevisiae, Candida glabrata e Candida krusei.

Em estudo realizado por Magalhães et al. (2011) com grãos de Kefir obtidos na região de Lavras-MG, foram isoladas 110 leveduras entre espécies de Saccharomyces sp. e de Candida sp., que foram identificadas por provas bioquímicas associadas a testes moleculares. Além disso, outras espécies de leveduras como Kluyveromyces sp., Pichia sp. e Zygosaccharomyces sp. foram reportadas em outras pesquisas com grãos de Kefir obtidos em outros países como Canadá e Estados Unidos da América (MIGUEL et al., 2012; AHMED et al., 2015), o que remete ao fato de que grãos obtidos em diferentes regiões podem apresentar constituições distintas em relação a população microbiana encontrada na matriz de polissacarídeos (LEITE et al., 2013) e ainda a necessidade de continuidade do presente estudo com o intuito de identificar biomolecularmente as leveduras isoladas.

Estudos recentes relatam a grande diversidade da comunidade microbiana presente nos grãos de Kefir. No entanto, também há estudos em que a diversidade microbiana presente nos grãos é baixa, nestes casos sendo descritos como micro-organismos isolados principalmente Saccharomyces spp., Kluyveromyces lactis, Kazachtania spp. e Candida spp. Pressupõe-se que tal discrepância seja oriunda das técnicas de caracterização microbiana empregadas, sendo as técnicas moleculares as mais sensíveis e avançadas para a detecção (LEITE, et al., 2012; DERTLI e ÇON, 2017; FIORDA et al., 2017).

Saccharomyces em grãos de Kefir podem apresentar comportamentos diferentes que são dependentes do substrato de fermentação. Quando em matrizes açucaradas tem seu crescimento estimulado pelo alto teor de sacarose do meio, uma vez que são capazes de converter a sacarose em glicose e frutose. Enquanto nas matrizes lácteas estimulam o crescimento de outras leveduras, pois as espécies de Saccharomyces não apresentam bom desempenho na conversão da lactose do 
meio em monossacarídeos. Apesar disto, S. cerevisiae não deixa de ser retratada como sendo a principal levedura fermenativa isolada de grãos de Kefir, contudo é encontrada em níveis baixos em comparação a outros micro-organismos (DERTLI e ÇON, 2017; FIORDA, et al., 2017).

Segundo Ceccato-Antonini e Sudbery (2004), S. cerevisiae sofre dimorfismo a partir de fatores ambientais em que se encontra, podendo adquirir várias formas. Ainda de acordo com os autores, essa capacidade oferece vantagens às células, como aumento da absorção de reagentes e/ou secreção de produtos, possibilitando sua aplicação em diferentes setores industriais. Acreditase que este fenômeno tenha sido observado nos exames diretos das colônias que apresentaram diferenças quanto as características microscópicas, porém macroscopicamente apontaram ser a mesma levedura.

Outros aspectos importantes com relação a essas leveduras são a capacidade de produção de enzimas de interesse biotecnológico, devido a facilidade de manipulação genética e a grande diversidade bioquímica que tornam estes micro-organismos uma excelente fonte enzimática, mostrando potencial em aplicações industriais.

As espécies de Candida sp. possuem grande importância clínica, entretanto algumas delas vêm mostrando potencial para a produção de fármacos e antifúngicos e para a produção de biossurfactantes. Em estudo realizado por Andrade (2015), observou-se que uma linhagem de Candida glabrata, isolada de solo semi-árido, foi capaz de produzir biossurfactante polimérico com alta composição de lipídeos, proteínas e carboidratos, demonstrando a potencialidade desse micro-organismo na aplicação em processos industriais (ANDRADE et al., 2015).

Com os avanços tecnológicos em engenharia genética, atualmente é possível clonar e expressar genes considerados incomuns em hospedeiros heterólogos, possibilitando a obtenção de produtos biotecnológicos e, consequentemente, a criação de organismos geneticamente modificados. Através da técnica de DNA recombinante, Domingues et al. (1999) conseguiu construir estirpes de $S$. cerevisiae capazes de metabolizar lactose possibilitando sua aplicação no tratamento do soro de queijo, um substrato tóxico para o meio ambiente e amplamente gerado por indústrias de laticínios. Além disso, construiu também estirpes de $S$. cerevisiae excretoras de $\beta$ galactosidase, enzima com importantes características para aplicações biotecnológicas (DOMINGUES et al., 2002).

\section{Conclusão}

Os grãos de Kefir são ricos em micro-organismos que podem trazer benefícios à saúde e que, quando isolados, podem ainda ser aplicados em processos biotecnológicos contribuindo para os avanços neste setor. Neste contexto, concluímos que foram isoladas leveduras dos gêneros Saccharomyces sp. e Candida sp. com grande relevância para processos biotecnológicos.

\section{Referências}

AHMED, Z.; WANG, Y.; AHMAD, A.; KHAN, S. T.; NISA, M.; AHMAD, H.; AFREEN, A. Kefir and Health: a contemporany perspective. Food Sci Nutr, v. 53, p. 422-434, 2015.

ANDRADE, R. F. S.; ANTUNES, A. A.; LIMA, R. A.; ARAÚJO, H. W. C.; RESENDESTOIANOFF, M. A.; FRANCO, L. O.; CAMPOS-TAKAKI, G. M. Enhanced Production of an Glycolipid Biosurfactant Produced by Candida glabrata UCP/WFCC1556 for Application in Dispersion and Removal of Petroderivatives. Int J Curr Microbiol App Sci, v. 4, p. 563-576, 2015. Disponível em: https://www.ijcmas.com/vol-47/Rosileide\%20F.S.\%20Andrade,\%20et\%20al.pdf. Acessado em 12 de outubro de 2017. 
ANVISA Módulo VII: Detecção e Identificação dos Fungos de Importância Médica. Disponível em: http://www.anvisa.gov.br/servicosaude/microbiologia/mod_7_2004.pdf. Acessado em 20 julho de 2016.

CARASI, P.; RACEDO, S. M.; JACQUOT, C.; ROMANIN, D. E.; SERRADELL, M. A.; URDACI, M. C. Impact ok Kefir derived Lactobacillus kefiri on the mucosal imune response and gut microbiota. J Immunol Res, v. 2015, p. 361604, 2014. Disponível em: https://www.hindawi.com/journals/jir/2015/361604/. Acessado em 12 de outubro de 2017.

CECCATO-ANTONINI, S. R.; SUDBERY, P. E. Filamentous growth in Saccharomyces cerevisiae. Braz J Microbiol, v. 35, p. 173-181, 2004. Disponível em: http://www.scielo.br/scielo.php?script=sci_arttext\&pid=S1517-83822004000200001. Acessado em 12 de outubro de 2017.

DERTLI, E.; ÇON, A. H. Microbial diversity of traditional kefir grains and their role on kefir aroma. Food Sci Technol, v. 85, p. 151-157, 2017.

DIOSMA, G.; ROMANIN, D. E.; REY-BURUSCO, M. F.; LONDERO, A.; GARROTE, G. L. Yeasts from kefir grains: isolation, identification, and probiotic characterization. World $\mathbf{J}$ Microbiol biotechnol, v. 30, p. 43-53, 2014.

DOMINGUES, L.; TEIXEIRA, J. A.; LIMA, N. Construction of a flocculent Saccharomyces cerevisiae fermenting lactose. Appl Microbiol Biotechnol, v. 51, p. 621-626, 1999.

DOMINGUES, L.; TEIXEIRA, J. A.; PENTTILÃ, H.; LIMA, N. Construction of a flocculent Saccharomyces cerevisiae strain secreting high levels of Aspergillus niger beta-galactosidase. Appl Microbiol Biotechnol, v. 58, p. 645-650, 2002.

FIORDA, F. A.; PEREIRA, G. V. M.; THOMAZ-SOCCOL, V.; RAKSHIT, S. K.; PAGNONCELLI, M. G. B.; VANDENBERGHE, L. P. S.; SOCCOL, C. R. Microbiological, biochemical, and functional aspects of sugary kefir fermentation - A review. Food Microbiol, v. 66, p. 86-95, 2017.

FRANCO, M. C.; GOLOWCZYC, M. A.; DE ANTONI, G. L.; PÉREZ, P. F.; HUMEN, M.; SERRADELL, M. L. A. Administration of kefir-fermented milk protects mice against Giardia intestinalis infection. J Med Microbiol, v. 62, p. 1815-1822, 2013. Disponível em: http://jmm.microbiologyresearch.org/content/journal/jmm/10.1099/jmm.0.068064-0\#tab2. Acessado em 12 de outubro de 2017.

GUZEL-SEYDIM, Z.; KOK-TAS, T.; GREENE, A. K.; SEYDIM, A. C. Review: functional properties of Kefir. Food Sci Nutr, v. 51, p. 261-268, 2011.

LEITE, A. M.; MAYO, B.; RACHID, C. T.; PEIXOTO, R. S.; SILVA, J. T.; PASCHOALIN, V. M. ; DELGADO, S. Assessment of the microbial diversity of Brazilian kefir grains by PCR-DGGE and pyrosequencing analysis. Food Microbiol., v. 31, p. 215-221, 2012. Disponível em: http://www.sciencedirect.com/science/article/pii/S0740002012000664. Acessado em 12 de outubro de 2017.

LEITE, A. M. O.; MIGUEL, M. A. L.; PEIXOTO, R. S.; ROSADO, A. S.; SILVA, J. T.; PASCHOALIN, V. M. F. Microbiological, techonological and therapeutic properties of Kefir: a 
natural probiotic beverage. Braz J Microbiol, v. 44, n. 2, p. 341-349, 2013. Disponível em: http://www.scielo.br/scielo.php?script=sci_arttext\&pid=S1517-83822013000200001. Acessado em 12 de outubro de 2017.

LEITE, A. M.; MIGUEL, M. A.; PEIXOTO, R. S.; RUAS-MADIEDO, P.; PASCHOALIN, V. M.; MAYO, B.; DELGADO, S. Probiotic potential of selected lactic acid bacteria strains isolated from Brazilian kefir grains. J Dairy Sci. v. 98, p. 3622-3632, 2015. Disponível em: http://www.journalofdairyscience.org/article/S0022-0302(15)00229-5/fulltext. Acessado em 12 de outubro de 2017.

MAGAlHÃES, K. T.; PEREIRA, G. V. M.; CAMPOS, C. R.; DRAGONE, G.; SCHWAN, F. Brazilian Kefir: structure, microbial communities and chemical composition. Braz J Microbiol, v. 42, p. 693-702, 2011. Disponível em: http://www.scielo.br/scielo.php?script=sci_arttext\&pid=S1517-83822011000200034. Acessado em 12 de outubro de 2017.

Miguel, M. G. C. P.; CARDOSO, P. G.; MAGALHÃES-GUEDES, K. T.; SCHWAN, R. F. Identification and assessment of Kefir yeast potential for sugar/etanol-resistance. Braz J Microbiol, v. 44, n. 1, p. 113-118, 2012. Disponível em: http://www.scielo.br/scielo.php?script=sci_arttext\&pid=S1517-83822013000100016. Acessado em 12 de outubro de 2017.

NIELSEN, B.; GURAKAN, G. C.; UNLU, G. Kefir: a multifaceted fermented dairy product. Probiotics Antimicrob Proteins, v. 6, p. 123-135, 2014.

PRADO, M. R.; BLANDÓN, L. M.; VANDENBERGHE, L. P. S.; RODRIGUES, C.; CASTRO, G. R.; THOMAZ-SOCCOL, V.; SOCCOL, C. R. Milk. Kefir: composition, microbial cultures, biological activities, and related products. Front Microbiol, v. 6, p. 1-7, article 1177, 2015. Disponível em: https://www.ncbi.nlm.nih.gov/pmc/articles/PMC4626640/. Acessado em 12 de outubro de 2017.

WESCHENFELDER, S.; PEREIRA, G. M.; CARVALHO, H. H. C.; WIEST, J. M. Caracterização físico-quiímica e sensorial de Kefir tradicional e derivados. Arq Bras Med Vet Zootec, v. 63, p. 473-480, 2011. Disponível em: http://www.scielo.br/scielo.php?script=sci_arttext\&pid=S010209352011000200027 . Acessado em 12 de outubro de 2017. 